\title{
Una llamada de alerta ante algunos de los denominados enfoques cualitativos en las investigaciones bibliotecológicas
}

\section{Emilio Setién Quesada}

Asociación Cubana de Bibliotecarios

\section{Resumen}

Se presentan los inconvenientes que pueden aflorar al utilizar algunos métodos cualitativos en investigaciones sobre el fenómeno bibliotecario, ignorando las relaciones cuantitativas y determinísticas presentes en él, según se identifican por la teoría bibliológico-informativa formulada por el autor.

Palabras clave: Métodos cualitativos. Fenómeno bibliotecario. Investigación bibliotecológica. Teoría bibliológico-informativa.

\section{Abstract}

Problems that may arise when using some qualitative methods in researches about library phenomenon, ignoring its quantitative and deterministic relations as described by the author's bibliological informative theory, are presented.

Key words: Qualitative methods. Library phenomenon. Bibliothecological research. Bibliological-informative theory.

Como se expone en el artículo titulado "Métodos cualitativos y cuantitativos en bibliotecología" (Setién, e. p.), las bibliotecas son el componente fundamental del fenómeno bibliotecario, entendiéndose este fenómeno como el conjunto de elementos que permiten conformar, facilitar y promover el uso de las colecciones de bibliotecas reales o virtuales, integradas por documentos de cualquier índole que registren los conocimientos y la actividad creadora de la humanidad, y que por su carácter e intención sean susceptibles de difusión o hayan sido difundidos. Comprende los espacios donde se realizan esos procesos y sus recursos humanos, materiales, financieros y tecnológicos, pero abarca también la legislación bibliotecaria, la literatura profesional, la formación de los bibliotecarios, sus asociaciones, las investigaciones sobre el sector y la propia estructura de la bibliotecología y su desarrollo teórico, histórico y metodológico, así como las propiedades, leyes y regularidades específicas del fenómeno bibliotecario, de sus elementos y de los procesos que tienen lugar en él, y sus interrelaciones con el entorno económico, 
político, histórico y cultural. Dentro de esta complejidad, es en las bibliotecas donde se presentan los sistemas de información cuya funcionalidad se incluye en los estudios de la bibliotecología. Tales sistemas (manuales, mecánicos o automatizados) ofrecen variables de interés para su estudio, que pueden ser contabilizadas con precisión y permiten aplicar procedimientos cuantitativos siempre y cuando los resultados obtenidos con ellos se interpreten desde una posición teórica acertada que permita conclusiones cualitativas coherentes.

Ahora bien, la interacción de las personas (lectores, principalmente) con esos sistemas de información, que se desarrolla en un contexto social complejo, puede ser estudiada mediante la aplicación de métodos cualitativos para describirla e interpretarla.

Por esa razón, a continuación se comentan ciertos inconvenientes que se presentan al aplicar los enfoques cualitativos en boga en las investigaciones bibliotecológicas, tomando como ejemplo las que se desarrollan al amparo del concepto de library and information science (LIS) (Budd, 2005; Hansson, 2005; Sundin y Johannisson, 2005). Estos inconvenientes se identifican desde las posiciones de la teoría bibliológico-informativa, que ha venido desarrollándose en Cuba desde la década de los ochenta del pasado siglo por el autor de este artículo con la colaboración de otros colegas, principalmente la del doctor Salvador Gorbea, investigador del Centro Universitario de Investigaciones Bibliotecológicas de la Universidad Nacional Autónoma de México (CUIB-UNAM) en la actualidad y la de la máster en ciencias Nuria Pérez Matos, investigadora de la Biblioteca Nacional José Martí de La Habana. La teoría ha sido objeto de distintas publicaciones, cada una de las cuales contiene determinadas precisiones con respecto a las anteriores. La más reciente de ellas apareció en 2003 bajo el sello de la editorial Félix Varela de Cuba (Setién, 2003). En el número de 2006 de Bibliotecas: Anales de Investigación, editado por la Biblioteca Nacional José Martí de La Habana, aparece un trabajo sobre los antecedentes, establecimiento, desarrollo y aplicaciones de esta concepción teórica y su trayectoria bibliográfica hasta el momento de la publicación (Setién, 2006). Están en proceso editorial, además "Nueva propuesta para la estructura de la bibliotecología en el contexto de la teoría bibliológico-informativa", "Niveles, fases y etapas del fenómeno archivístico y "Niveles, fases y etapas del fenómeno bibliográfico". En estos artículos se incluyen los desarrollos más recientes de la teoría. Los dos últimos reflejan parte de los resultados de una investigación que este autor tiene comprometida con el CUIB.

Ya en trabajos previos (Setién, 2003) se habían apuntado algunas diferencias del enfoque hermenéutico fenomenológico presentado por Budd (2005) con respecto al discurso bibliotecológico marxista en el que se inserta la teoría bibliológicoinformativa. Ahora se amplían las implicaciones de esas diferencias.

Scire. 12 : 2 (jul.-dic. 2006) 69-73. ISSN 1135-3716. 
Primero, el enfoque hermenéutico fenomenológico rechaza el enunciado de leyes propias del fenómeno bibliotecario. John M. Budd lo considera como un fundamento para sustituir al positivismo. Lo presenta como una "descripción de estado mental y su expresión pública", que abre posibilidades al investigador en lugar de llevarlo por caminos establecidos. Así concebido, este enfoque no se interesa por el enunciado de relaciones que tengan carácter determinístico. De esta forma se pierde un elemento esencial para sustentar la personalidad de la bibliotecología como disciplina y su carácter científico, en tanto son precisamente las leyes fundamentales que rigen el comportamiento de un fenómeno dado las que definen el método propio de la disciplina que lo estudia, singularizándola, y las que explican las relaciones causales entre los elementos del fenómeno y entre este y su entorno. El método propio de la bibliotecología se expresa, pues, en el enunciado de su ley general y en el del principio o contradicción fundamental del fenómeno bibliotecario. La ley general de la bibliotecología se formula como la concatenación general y regular que existe entre los elementos del fenómeno bibliotecario (1) y las condiciones socioeconómicas, así como su necesaria correspondencia, mediada por las características de la producción y difusión de documentos propios de las colecciones de bibliotecas y su demanda, o la de sus contenidos.

Un ejemplo de la correspondencia entre las condiciones económicas, políticas, históricas y culturales y el fenómeno bibliotecario se puede observar en las épocas en que se divide su comportamiento en Cuba. En ellas se observa cómo a cada época le corresponden cualidades peculiares distintas del fenómeno, acordes con las condiciones antes mencionadas, imperantes en cada una de ellas: $a$ ) primera época: período colonial y república mediatizada hasta la Revolución del 33 (etapa fundacional, de lento desarrollo y de erudición); b) segunda época: desde la Revolución del 33 hasta la del 59 (etapa de expansión irregular y profesionalización); c) tercera época: desde la Revolución del 59 hasta principios del siglo XXI (etapa de consolidación, diversificación y cientificidad).

Esta correspondencia es mucho más evidente cuando se analiza el comportamiento del fenómeno en periodos más cortos (Setién y Pérez, 2004).

El principio fundamental del fenómeno bibliotecario viene dado por la necesaria correspondencia entre las colecciones de biblioteca y las demandas de los documentos que las integran o de los datos e ideas contenidos en ellos. Este principio refleja la contradicción dialéctica no antagónica interna que impulsa el desarrollo del fenómeno y permite evaluar su efectividad social.

Por otra parte, el enfoque hermenéutico fenomenológico sitúa a las bibliotecas en su interacción con el medio como el objeto de estudio de LIS, lo que es acertado en principio. Pero en las relaciones de la institución con el medio hay que tener en cuenta tres tipos de factores: $a$ ) los que son parte también del fenómeno bibliotecario, como la legislación bibliotecaria, la literatura profesional, la formación 
de los bibliotecarios, sus asociaciones, las investigaciones sobre el sector, que no se producen necesariamente en la institución; $b$ ) los que vinculan a la institución de forma inmediata con las etapas del ciclo de circulación social de la información documental denominadas difusión de documentos y demandas de documentos propios de bibliotecas (2) o de los datos e ideas contenidos en ellos (3); c) los que la relacionan de forma más mediata con las condiciones económicas, políticas, históricas y culturales que prevalecen en su medio, en las que se originan los problemas o situaciones que generan necesidades e intereses informativos y conducen a demandas de documentos o de la información contenida en ellos, por una parte, y a la creación de información y a la creación, producción y difusión de documentos donde aquella se registra, por otra.

Esta estratificación es necesaria porque define distintos grados de influencia de las relaciones entre la institución y su entorno. Influencia del entorno que determina el de la institución. Participación de la institución en la transformación de su medio.

Luego, cuando se aplica el enfoque hermenéutico fenomenológico al estudio de las relaciones de los sistemas informativos de las bibliotecas con los lectores, se logra conocer un comportamiento fenoménico, pero se corre el riesgo de no desvelar las razones esenciales y verdaderas que conducen a ese comportamiento, si no se tienen en cuenta aquellos elementos que lo condicionan y que se identifican tanto en la ley general de la bibliotecología como en el principio fundamental del fenómeno bibliotecario.

Por otra parte, en el enfoque hermenéutico fenomenológico se reconoce el carácter dialéctico del conocimiento. Se habla, incluso, de una espiral hermenéutica, pero no se reconoce que ese movimiento en espiral es reflejo de la realidad objetiva que se desarrolla en un movimiento dialéctico ascendente y que, en términos del marxismo, se denomina espiral dialéctica (Setién y Pérez, 2004).

Finalmente obsérvese que, a pesar de que el enfoque hermenéutico fenomenológico se introduce en las investigaciones de LIS, según Budd (1995), como un fundamento para sustituir diversas posiciones positivistas, estas persisten aún de alguna forma. Así se aprecia en el artículo de Sundin y Johannisson (2005) destinado a mostrar cómo el neopragmatismo, combinado con una perspectiva sociocultural, ofrece a LIS una fuerte herramienta epistemológica. Y el neopragmatismo es, precisamente, la corriente filosófica que une las ideas del pragmatismo con las del neopositivismo.

\section{Notas}

(1) Elementos esenciales: colecciones de bibliotecas, demandas de los documentos propios de bibliotecas o sus contenidos, circulación interna, externa o a distancia de esos documentos o sus contenidos. Elementos históricos: legislación bibliotecaria, investiga- 
ciones y publicaciones bibliotecológicas, formación del bibliotecario, asociaciones profesionales.

(2) Como ya se apuntó al definir el fenómeno bibliotecario, los documentos propios de la biblioteca son aquellos que plasman el conocimiento acumulado y la actividad creadora de la humanidad y que han sido difundidos o concebidos para su difusión.

(3) Cf. Setién (2003, pp. 16, 23, 25 y 26). Véase allí la representación grafica de los componentes del fenómeno bibliotecario y sus relaciones con el medio, así como la del ciclo de circulación social de la información utilizado en la obra.

\section{Referencias}

Budd, J. M. (1995). An epistemological foundation for library and information science. // Library Quarterly. 65:3 (1995) 295-318.

Budd, J. M. (2005). Phenomenology and information studies. // Journal of Documentation. 61:1 (2005) 44-59. http://www.emeraldinsight.com/10.1108/002204105105780 (200512-29).

Hansson, J. (2005). Hermeneutics as a bridge between the modern and the postmodern in library and information science. // Journal of Documentation. 61:1 (2005) 102-113. http://www.emeraldinsight.com/10.1108/00220410510578032 (2005-12-29).

Setién, E. (2003). Teoría bibliológico informativa. La Habana: Félix Varela, 2003.

Setién, E. (2006). Raíces y concepciones que conducen a la formación de la teoría bibliológico-informativa. // Bibliotecas: Anales de Investigación. 1:1 (2006).

Setién, E. (e. p.). Métodos cualitativos y cuantitativos en bibliotecología. // Ciencias de la Información. La Habana, e. p.

Setién, E.; Pérez Matos, N. (2004). Regularidades y leyes generales bibliológico-informativas: sus manifestaciones en Cuba. // CD-ROM info 2004. La Habana: IDICT, 2004.

Sundin, O.; Johannisson, J. (2005). Pragmatism, neo-pragmatism and sociocultural theory: communicative participation as a perspective in LIS. // Journal of Documentation. 61:1 (2005) 23-43. http://www.emeraldinsight.com/10.1108/00220410510577998 (200512-29).

Scire. $12: 2$ (jul.-dic. 2006) 69-73. ISSN 1135-3716. 